\title{
Vicisitudes de la práctica de enfermería ante la Covid-19
}

\author{
Vicissitudes in the nursing practice in \\ the face of Covid-19 pandemic
}

\section{Vicissitudes da prática de enfermagem perante a COVID-19}

Lejano parece el mes de enero cuando estábamos saliendo de las festividades decembrinas y con gran expectativa y emoción recibíamos un año nuevo. Iniciaba el 2020, especial pues es nuestro Año Internacional de los Profesionales de la Enfermería y de la Partería, designado así por la $72^{\mathrm{a}}$ Asamblea Mundial de la Salud en conmemoración del bicentenario del natalicio de Florence Nightingale.

Para esta celebración nuestro gremio concertó reuniones de trabajo, inició la planificación tanto de eventos magnos como de actividades académicas y contactó a importantes conferencistas para tener el mejor programa posible. Era la oportunidad de hacer patente que nuestra labor profesional es imprescindible y cumple una importante función dentro del sistema de salud.

Sin embargo, a inicios de este año la OMS reportó la existencia de un brote de neumonía atípica en la ciudad china de Wuhan. Se trataba del surgimiento de lo que posteriormente sería la pandemia de la Covid-19, ocasionada por un nuevo tipo de Coronavirus del que se advertía, podría convertirse en un serio problema de salud pública internacional².

En ese entonces las noticias parecían tan distantes que creímos que esta enfermedad no nos impactaría. Pese a ello, estuvimos al pendiente del avance de la epidemia, de las tasas de contagio, así como de su letalidad; sentimos algo de tranquilidad porque la mortalidad se mantenía baja pues se localizaba principalmente en Asia. La preocupación comenzó a aumentar cuando se reportaron múltiples casos y muertes tanto en Europa Central como en Estados Unidos. En México, las autoridades sanitarias confirmaron el primer caso positivo del nuevo Coronavirus a finales del mes de febrero, se trataba de un hombre de 35 años que había asistido a un congreso en Italia3. A partir de ese anuncio todo cambió, la normalidad que conocíamos estaba por desaparecer.

Marzo llegó a la par de los primeros casos sospechosos de la Covid-19 atendidos en el Centro Médico Nacional de Occidente (CMNO). El SARS-CoV-2 nos encontró con gran incertidumbre, temor, desconocimiento y enojo, sentimientos exacerbados por el bombardeo de toda clase de noticias, algunas contradictorias, que nos llevaron a padecer infodemia4. El proceso de reconversión de las 
unidades que prestaron atención a estos pacientes fue el primero de muchos retos que tuvimos que enfrentar: el aprovisionamiento del equipo disponible; determinar los consumos mínimos de material; elección y adecuación de las áreas de atención; la resolución a contra reloj de diversos problemas en la infraestructura hospitalaria; decidir las rutas de traslado; definir y detallar los procesos de atención; y un largo etcétera de actividades necesarias para hacer frente a la crisis anunciada. Pese a 42 años de historia del hospital, nos dimos cuenta que la pandemia había pasado facturas, se tenía que gestionar la adversidad.

Se habilitó un primer piso destinado a enfermos Covid y llegó la necesidad de seleccionar a la plantilla del personal de enfermería para la atención de los pacientes que ingresaran con sospecha de portar la enfermedad. En ese momento cruzábamos los dedos esperando que la demanda se contuviera en ese único piso, pero la realidad nos pegó de frente.

La demanda de atención fue in crescendo y con ello las complicaciones de mantener una plantilla suficiente, pues se vio mermada por el personal con factores de riesgo quienes tuvieron que marcharse a casa para evitar contraer la enfermedad. Para sostener la atención se recurrió al apoyo del personal de los servicios y departamentos que pararon sus actividades habituales a causa del proceso de reconversión. Se trataba de profesionales con poca o nula experiencia en el cuidado de pacientes en condición grave, o en muchos casos en estado crítico.

Dicha situación ha sido una constante a nivel mundial, lo que pone de manifiesto la imperiosa necesidad de tener disponible a los profesionales de enfermería necesarios y suficientes, con formación de práctica avanzada, que permitan mejorar la calidad y la seguridad en la atención de los pacientes en los servicios de salud'5.

Durante los meses de abrily mayo nos fue evidente que la Covid-19 es una enfermedad de trayectoria muy variable, con alta contagiosidad y patogenicidad que puede cursar de manera asintomática hasta casos muy graves; siendo el Síndrome de Dificultad Respiratoria Aguda, sepsis y falla orgánica múltiple las complicaciones más frecuentes ${ }^{6}$. El cuidado de enfermería en estas circunstancias se vuelve extremadamente difícil y requiere de altos estándares de atención a fin de prevenir riesgo de contagio o resultados críticos en los pacientes7. La respuesta a dicha situación produjo la rápida programación de jornadas intensivas de capacitación para el 100\% del personal de la Unidad Covid del CMNO.

Nunca antes se movieron tantas voluntades y esfuerzos de muchos profesionales para dar a conocer protocolos, medidas preventivas, así como medidas de contención y seguridad. El foco principal de la capacitación fue hacia los equipos que estarían en la primera línea de atención del paciente con Covid. Ardua es la tarea, ya que en los primeros momentos fuimos increpados y cuestionados, también fuimos testigos mudos del temor producido por la infodemia en muchos de nuestros propios compañeros.

Junio y julio fueron meses demandantes en los que nos tuvimos que reinventar, nos adaptamos y cambiamos de acuerdo con las necesidades a que nos fue obligando la pandemia. Tuvimos que reaprender procedimientos tan básicos como el colocarse y retirarse el equipo de protección personal, a tal punto de volvernos obsesivos y meticulosos con la higiene de manos, nos hicimos expertos en cubrebocas y respiradores. Incluso aprendimos a marchas forzadas cómo abordar de manera segura la vía aérea, así como a manejar ventiladores mecánicos. El ejercicio de la enfermería en este contexto nos reveló nuestras deficiencias en la formación y en los procesos de trabajo, obligándonos a innovar, entrenarnos y capacitarnos de manera intensiva para cuidar a muchos; esto es un escenario para el que la universidad no nos preparó. ${ }^{8}$ 
Ha transcurrido medio año y la vida familiar ha cambiado para todos. Los días pasan indistinguibles, uno tras otro, arrastrándonos en la misma rutina. Los fines de semana ya no son distintos. Nos hemos tenido que alejar de nuestros seres queridos, aunque tratamos de acortar esa brecha con tecnología, esta nunca sustituirá la cercanía y el contacto físico. En el hospital las jornadas de trabajo se experimentan como una eternidad, con alto grado de estrés y con escasez de recursos de todo tipo. Viviendo con lo mejor y también con lo peor del personal de salud.

Recientemente he leído un texto que me ha hecho reflexionar sobre cómo al ser parte del personal de salud hemos vivido esta pandemia desde dos roles: el de ser cuidadores y el de ser enfermos. En ambos casos se enfrentan los mismos problemas, se comparte el mismo aislamiento, el mismo riesgo, el mismo miedo y la misma incertidumbre frente a la Covid-19. Sufrimos lamentables pérdidas de compañeros, amigos y familia; hemos tenido que recuperarnos física, emocional y espiritualmente; retornamos cada día al mismo escenario laboral y continuaremos con esta batalla hasta que exista la posibilidad de una vacuna que permita el control del SARS-CoV-2. Debemos asumir el reto de proporcionar un cuidado integral con objetivos claramente definidos: recuperar la salud de los pacientes ${ }^{7}$.

\author{
O.V. Orozco-López \\ ORCID: 0000-0001-8742-3660 \\ Subjefa de Enfermería del \\ Centro Médico Nacional de Occidente \\ Unidad Médica de Alta Especialidad Hospital de Especialidades \\ Instituto Mexicano del Seguro Social, \\ Guadalajara, Jalisco, México \\ verozcolopez@gmail.com
}

\title{
REFERENCIAS
}

1. Organización Panamericana de la Salud. Washington, DC: OPS; C2O2O. 2O2O: Año Internacional de los profesionales de enfermería y partería. https://bit.ly/2Fid3vc

2. The BBC. United Kingdom: The BBC News; c2O2O. Coronavirus disease named Covid-19. https://bbc.in/3hootYr

3. Agencia EFE. Madrid, España: Agencia EFE; C2O2O. México registra primer caso de COVID-19 entre recuerdos de pandemia por AH1N1. https://bit.ly/3kaWNv3

4. Repositorio Institucional para intercambio de información. Washington, D.C.: OPS; c2O2O. Entender la infodemia y la desinformación en la lucha contra la COVID-19. https://bit.ly/2RkYLMQ

5. World Health Organization. Geneva: WHO; c2O2O. State of the world's nursing 2O2O: Investing in education, jobs and leadership. https://bit.ly/3huT2yY

6. Díaz-Castrillón FJ, Toro-Montoya AI. SARS-CoV-2/COVID-19: el virus, la enfermedad y la pandemia. Med. lab. 2020; 24(3): 183-205. https://doi.org/10.36384/01232576.268

7. Fundación Cardioinfantil-Instituto de Cardiología. Bogotá, Colombia: Fundación CardioinfantilNoticias; c2019. Retos de enfermería durante la pandemia por COVID-19. https://bit.ly/3hqcdKc

8. Sacristán JA, Millán J. El médico frente a la COVID-19: lecciones de una pandemia. Educ. med. 202O; 21(4): 265-71. https://dx.doi.org/10.1016\%2Fj.edumed.2020.06.002 